\title{
Partial synthetic models of FeMoco with sulfide and carbyne ligands: Effect of interstitial atom in nitrogenase active site
}

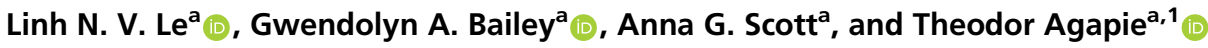

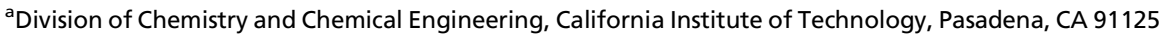

Edited by Marcetta Y. Darensbourg, Texas A\&M University, College Station, TX, and approved October 26, 2021 (received for review May 20, 2021)

\begin{abstract}
Nitrogen-fixing organisms perform dinitrogen reduction to ammonia at an Fe-M ( $M=M o$, Fe, or $\mathrm{V}$ ) cofactor (FeMco) of nitrogenase. FeMco displays eight metal centers bridged by sulfides and a carbide having the $\mathrm{MFe}_{7} \mathrm{~S}_{8} \mathrm{C}$ cluster composition. The role of the carbide ligand, a unique motif in protein active sites, remains poorly understood. Toward addressing how the carbon bridge affects the physical and chemical properties of the cluster, we isolated synthetic models of subsite $\mathrm{MFe}_{3} \mathrm{~S}_{3} \mathrm{C}$ displaying sulfides and a chelating carbyne ligand. We developed synthetic protocols for structurally related clusters, $\left[\mathrm{Tp}^{*} \mathrm{M}^{\prime} \mathrm{Fe}_{3} \mathrm{~S}_{3} \mathrm{X}\right]^{\mathrm{n}-}$, where $\mathrm{M}^{\prime}=\mathrm{Mo}$ or $\mathrm{W}$, the bridging ligand $X=C R, N, N R, S$, and Tp* $=$ Tris(3,5-dimethyl-1-pyrazolyl)hydroborate, to study the effects of the identity of the heterometal and the bridging $X$ group on structure and electrochemistry. While the nature of $\mathrm{M}^{\prime}$ results in minor changes, the chelating, $\mu_{3}$-bridging carbyne has a large impact on reduction potentials, being up to $1 \mathrm{~V}$ more reducing compared to nonchelating $\mathrm{N}$ and $\mathrm{S}$ analogs.
\end{abstract}

FeMoco model | nitrogenase | carbide clusters | reduction potential | iron-sulfur clusters

B iological dinitrogen conversion to ammonia is performed by nitrogenases, a class of enzymes displaying several complex iron-sulfur clusters (1). The site of $\mathrm{N}_{2}$ reduction in the most efficient nitrogenase is a heterometallic cluster displaying $\mathrm{Fe}$ and Mo, the iron-molybdenum cofactor (FeMoco) (1). Two other nitrogenases are known where $\mathrm{Fe}$ or $\mathrm{V}$ are found at the Mo position. FeMoco consists of $\mathrm{Fe}_{4} \mathrm{~S}_{3} \mathrm{C}$ and $\mathrm{MoFe}_{3} \mathrm{~S}_{3} \mathrm{C}$ cubanes with $\mu_{3}$-sulfides joined together by a shared interstitial $\mu_{6}$-carbide and three additional sulfides that bind in $\mu_{2}$-fashion (Fig. 1) (2). The impact of the carbide ligand on the electronic structure and reactivity of the cofactor, and therefore its role in the catalytic cycle of $\mathrm{N}_{2}$-to- $\mathrm{NH}_{3}$ conversion, is unclear (3). The carbide ligand is not lost during catalysis, and it has been suggested that it becomes protonated before $\mathrm{N}_{2}$ activation (3). To address the effect of carbon-based ligands for $\mathrm{N}_{2}$ activation, such as providing electronic stabilization and structural flexibility to accommodate multielectron redox processes, synthetic models have included arene (4), $N$-heterocyclic carbene (5), aryl (6), and alkyl $(7,8)$ donors in mononuclear iron complexes.

$\mathrm{Bi}$ - and multimetallic synthetic analogs focused on interrogating the role of the interstitial atom and multimetallic effects have been targeted $(7,9-23)$, but complexes that display bridging carbide $(11,24-27)$ or even carbyne $(9,10,28)$ ligands are rare. Carbide-containing Fe clusters display four to six metal centers but invariably are rich in CO ligands $(24,25,27)$. The presence of this strong field donor limits the comparison to FeMoco given the significantly different electronic structure conferred by the weak field sulfides. Moreover, the formal oxidation state of the $\mathrm{Fe}$ centers is significantly more reduced, between $\mathrm{Fe}^{0}$ and $\mathrm{Fe}^{\mathrm{II}}$, than in the protein, between $\mathrm{Fe}^{\mathrm{II}}$ and $\mathrm{Fe}^{\mathrm{III}}$ (2). Recent promising advances have been made toward the incorporation of sulfide ligands into carbide-containing iron carbonyl clusters $(10,11)$. In order to gain a more accurate understanding of the impact of the carbide on the properties of clusters related to FeMoco, metal complexes structurally related to the biological active site that are multimetallic, have multiple sulfide ligands and few CO ligands, and display bridging carbon-based ligands and oxidation states of $\mathrm{Fe}^{\mathrm{II}}-\mathrm{Fe}^{\mathrm{III}}$ are desirable.

Toward developing synthetic methodologies to structures analogous to FeMoco that include a bridging carbon donor, we focus our initial efforts on the cubane subsite, $\mathrm{MoFe}_{3} \mathrm{~S}_{3} \mathrm{C}$ (Fig. 1, Top Row). Because the nature of the $\mu_{2}$-bridging ligands in FeMoco is variable, with sulfide, selenide (29), CO (30), or NH (31) (for FeVco) moieties at these positions as characterized by crystallography, the primary target was to match the composition of the cubane core. In this work, we present the preparation of a series of heterometallic ironsulfur cubane-type clusters containing Mo or W with biologically relevant $\mu_{3}$ bridging ligands $X(X=N, N R, C R$, and $S)$ incorporated at the $\mathrm{Fe}_{3}$ face-including examples bearing a bridging CR ligand. These variations in the bridging ligand result in a large shift in the biologically relevant $\mathrm{M}^{\prime} \mathrm{Fe}_{3}{ }^{11+}$ / $\mathrm{M}^{\prime} \mathrm{Fe}_{3}{ }^{10+}$ redox couple of up to $2 \mathrm{~V}$, with the most reducing system occurring for the cluster bearing a bridging carbyne. These results suggest an important role of the interstitial carbide ligand in FeMoco in modulating the electronic properties of the cluster toward rendering it more reducing and potentially more reactive in $\mathrm{N}_{2}$ activation and conversion into $\mathrm{NH}_{3}$.

\section{Significance}

Nitrogen, a common component of biomolecules, is sourced from abundant dinitrogen in the atmosphere through conversion to ammonia. Organisms capable of fixing $\mathrm{N}_{2}$ employ nitrogenases, metalloproteins that display metal-sulfide clusters that facilitate electron transfers and substrate activation. The site of $\mathrm{N}_{2}$ conversion to $\mathrm{NH}_{3}$ is FeMco $(\mathrm{M}=\mathrm{Mo}$, $\mathrm{Fe}$, or $\mathrm{V}$ ), a cluster of notable complexity in bioinorganic chemistry, which displays an unusual interstitial carbon ligand. The function of this bridging ligand remains unclear, and systematic structure-function studies with bridging C-donors are challenged by a lack of synthetic methods for analogous clusters. Herein, we report the first synthetic cluster that models a cubane moiety of FeMco bearing a chelating carbyne ligand and related structure-property studies.

Author contributions: L.N.V.L., G.A.B., A.G.S., and T.A. designed research; L.N.V.L., G.A.B., and A.G.S. performed research; L.N.V.L., G.A.B., A.G.S., and T.A. analyzed data; L.N.V.L., G.A.B., A.G.S., and T.A. wrote the paper; and T.A. mentored researchers. The authors declare no competing interest.

This article is a PNAS Direct Submission.

Published under the PNAS license.

${ }^{1}$ To whom correspondence may be addressed. Email: agapie@caltech.edu.

This article contains supporting information online at http://www.pnas.org/lookup/ suppl/doi:10.1073/pnas.2109241118/-/DCSupplemental.

Published December 2, 2021. 



Fig. 1. (Top) Structure of FeMoco in Mo-dependent nitrogenase from the Protein Data Bank structure 3U7Q with a blue circle emphasizing the cubane subsite and its schematic representation highlighting in color the subsite of focus in this study. (Bottom) Carbyne and carbide-containing model complexes (9-11).

\section{Results and Discussion}

To rationally incorporate different ligands at the $\mu_{3}$-bridging position corresponding to the carbide, a $\mathrm{WFe}_{3} \mathrm{~S}_{3}$ cluster supported by a W-coordinated Tp* ligand, $\mathbf{1 - W}$, was selected as precursor bearing a $\mu_{3}-\mathrm{Cl}$ at the carbide position (Fig. 2) (32). Although heterometallic iron-sulfur clusters of the $\mathrm{MFe}_{3}$ types have been reported with $\mathrm{M}=\mathrm{V}, \mathrm{Mo}$, and $\mathrm{W}$, they typically display a $\mu_{3}-\mathrm{S}$ vertex opposite the heterometal that is difficult to substitute with other donor types relative to chloride $(33,34)$. Indeed, starting from a $\mu_{3}-\mathrm{Cl}$ precursor offers a versatile route to incorporating biologically relevant light atoms at the bridging position by ligand metathesis reactions (32). As an example, the $\mu_{3}-\mathrm{Cl}$ ligand can be substituted with $\mu_{3}-\mathrm{S}$ or $\mu_{3}-\mathrm{NSiMe}_{3}$ by oxidative metathesis with $\mathrm{S}_{8}$ or $\mathrm{Me}_{3} \mathrm{SiN}_{3}$, respectively (32).

For the installation of a carbon-based ligand at the $\mu_{3}$ position, we were inspired by the utilization of the strained carbene bis(diisopropylamino)cyclopropenylidene (BAC) (35) for promoting $\mathrm{C}$-atom transfer to the $\mathrm{Fe} \equiv \mathrm{N}$ bond of the iron(IV) nitride $\left[\left\{\mathrm{PhB}\left({ }^{\mathrm{i}} \mathrm{Pr}_{2} \mathrm{Im}\right)_{3}\right\} \mathrm{Fe}(\mathrm{N})\right]\left({ }^{\mathrm{i}} \mathrm{Pr}_{2} \mathrm{Im}=1,2\right.$-diisopropylimidazolylidene) (36). This ultimately generated a cyanide ligand, with the release of alkyne ${ }^{\mathrm{i}} \mathrm{Pr}_{2} \mathrm{NC} \equiv \mathrm{CN}^{\mathrm{i}} \mathrm{Pr}_{2}$ as the side product. Mixing 1-W with 3 equivalents of $\mathrm{BAC}$ in tetrahydrofuran
(THF) in the presence of $\mathrm{NaBPh}_{4}$ as a chloride abstracting agent results in the gradual disappearance of the insoluble 1-W to form a dark red solution, along with the precipitation of a colorless solid, assigned as $\mathrm{NaCl}$ (Fig. 2). Upon filtration, the vapor diffusion of pentane into the filtrate over one day leads to the formation of dark purple needles. A single crystal X-ray diffraction (XRD) study of these crystals confirmed the structure of the product, where the three terminal chlorides have been substituted with BAC to give a monocationic cluster, 2-W, with a $\mathrm{BPh}_{4}$ counteranion (Fig. 2). Although $\mathrm{MFe}_{3} \mathrm{~S}_{3}$ clusters supported by carbene ligands have not been structurally characterized, the $\mathrm{Fe}-\mathrm{C}$ distances are in the range of $\mathrm{Fe}_{4} \mathrm{~S}_{4}$ clusters supported by NHC ligands $(15,37)$.

In order to promote the delivery of a $\mathrm{C}$ atom or $\mathrm{CR}$ group, at least one C-C bond has to be cleaved, which can be achieved by methods such as heating (38), photolysis (38), or reduction $(36,39)$. While 2-W remains unchanged when irradiated with a 75-W Xe lamp and decomposes when heated at reflux in THF under an inert atmosphere, reduction with one equivalent of a strong reducing agent like potassium naphthalenide leads to the new cluster 3 . Instead of generating a neutral, one-electron reduced form of $\mathbf{2 - W}$ and $\mathrm{KBPh}_{4}$ as byproduct, product $\mathbf{3}$ loses

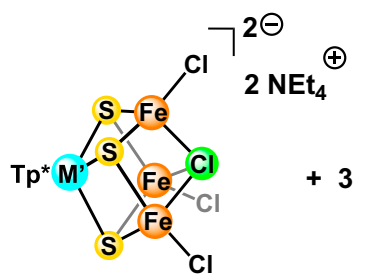

1-M' (M' = W or Mo) $\left(\mathrm{M}^{\prime} \mathrm{Fe}_{3}\right)^{9+}$

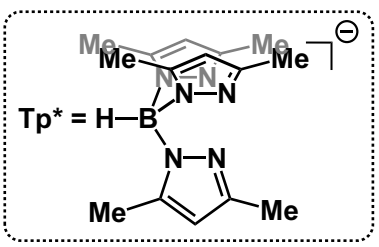

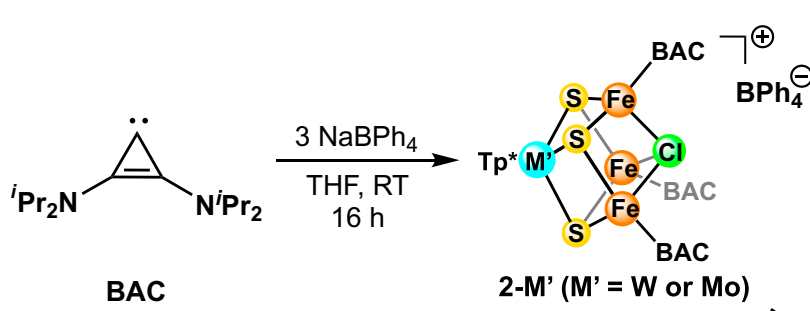

BAC
$3.1 \mathrm{KC}_{8}$ THF, RT, $16 \mathrm{~h}$

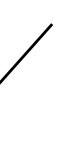

$\left(\mathrm{M}^{\prime} \mathrm{Fe}_{3}\right)^{9+}$
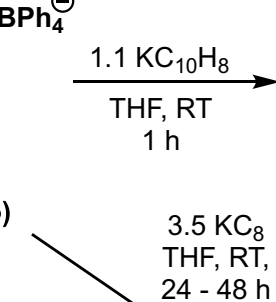

$3.5 \mathrm{KC}_{8}$ THF, RT,

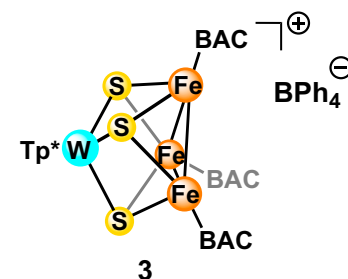
3 $\left(\mathrm{M}^{\prime} \mathrm{Fe}_{3}\right)^{8+}$ $1.5 \mathrm{KC}_{8}$ THF, RT, $48 \mathrm{~h}$ $\downarrow$

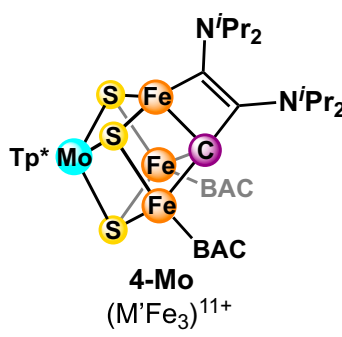

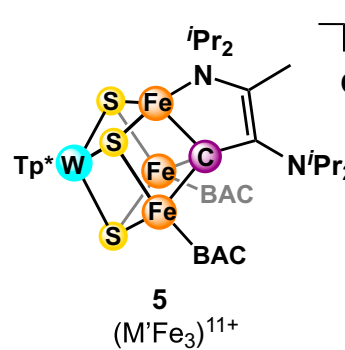
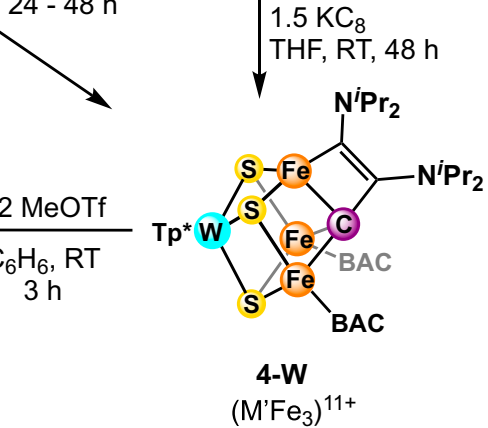

Fig. 2. Synthesis of carbyne-containing clusters. 
the $\mu_{3}-\mathrm{Cl}$ ligand as $\mathrm{KCl}$ likely driven by precipitation, leaving an open triangular $\mathrm{Fe}_{3}$ face, as demonstrated by XRD characterization (Fig. 2).

Cluster 3 possesses a rare incomplete cubane geometry for iron-sulfur clusters. The related $\left[\mathrm{Fe}_{4} \mathrm{~S}_{3}\right]$ geometry has only been reported in the anion $\left[\mathrm{Fe}_{4} \mathrm{~S}_{3}(\mathrm{NO})_{7}\right]^{-}$of Roussin's black salt (40) in inorganic compounds, and an oxygen-tolerant [NiFe]-hydrogenase in biology (41). Incomplete heterometallic cubanes of the form $\mathrm{M}^{\prime} \mathrm{Fe}_{3} \mathrm{~S}_{3}$ have only been observed for $\mathrm{M}^{\prime}=$ Mo in a synthetic system, where the $\mathrm{Fe}$ atoms are ligated by multiple $\mathrm{CO}$ ligands (42). The open-face $\mathrm{Fe}_{3}$ triangle resembles the sulfidefree triiron systems supported by multinucleating trisamide ligands, which can bind $\mu_{3}$-nitride or $\mu_{3}$-imide moieties $(14,43)$. Thus, the open nature of the $\mathrm{Fe}_{3}$ cluster face in 3 makes it a promising platform for the rational installation of various bridging ligands in a $\mu_{3}$ mode.

Cluster 3 can further be reduced with an excess of $\mathrm{KC}_{8}$ to form the neutral, $\mathrm{Et}_{2} \mathrm{O}$ soluble cluster 4-W. Gratifyingly, under these highly reducing conditions, the $\mathrm{C}-\mathrm{C}$ bond in the $\mathrm{BAC}$ ligand is cleaved and the cyclopropene ring opens, delivering a carbyne ligand to the bridging position. The cluster loses its $\mathrm{C}_{3}$ symmetry, resulting in two $\mathrm{Fe}$ atoms ligated by $\mathrm{BAC}$ and a unique $\mathrm{Fe}$ center, to which the rest of the ring-opened $\mathrm{BAC}$ ligand anchors as a vinyl fragment. This is an example of a synthetic iron-sulfur cluster without CO ligands that displays a carbyne donor. Aside from the bridging carbyne ligand, the terminal hydrocarbyl ligand is also notable, given the role of such ligands in SAM enzymes (44) and their scarcity in synthetic iron-sulfur cluster chemistry (45). Conveniently, $\mathbf{4 - W}$ can also be synthesized directly from $\mathbf{2}-\mathbf{W}$ using an excess of $\mathrm{KC}_{8}$ or potassium naphthalenide without isolating $\mathbf{3}$. This reaction stops at $\mathbf{3}$ if conducted at $-78^{\circ} \mathrm{C}$ for $1 \mathrm{~h}$, while appreciable conversion to $4-\mathrm{W}$ can only be achieved at room temperature over longer reaction times, suggesting that the ring opening and rearrangement of the BAC ligand is rate-limiting. The vinyl ligand in $\mathbf{4 - W}$ can be alkylated with MeOTf, leading to a five-membered amine-carbyne chelate with $\mathrm{N}^{\mathrm{i}} \mathrm{Pr}_{2}$ bound to the unique Fe (Fig. 2). This cluster is reminiscent of a putative $\mathrm{NH}_{3}$-bound form of FeMoco, as it displays a bridging $\mathrm{C}$-based ligand and a nitrogen donor at one of the $\mathrm{Fe}$ centers.

Toward preparing structural analogs of the $\mu_{3}$-carbyne ligand, 3 was investigated as a precursor to a cluster bearing $\mathrm{N}$ or $\mathrm{S}$ at the bridging position. Treatment of 3 with $\mathrm{NBu}_{4} \mathrm{~N}_{3}, \mathrm{Me}_{3} \mathrm{SiN}_{3}$, and $\mathrm{PPh}_{3} \mathrm{~S}$ (or $\mathrm{S}_{8}$ ) leads to the formation of the corresponding nitride- (6), imide- (7), and sulfide- (8) bridged clusters (Fig. 3). Complexes 6, 7, and 8 are isostructural, with a $\mathrm{WFe}_{3} \mathrm{~S}_{3} \mathrm{X}(\mathrm{X}=\mathrm{N}$ or S) cubane supported by $\mathrm{Tp}^{*}$ at $\mathrm{W}$ and one BAC ligand bound to each iron center (Fig. 4). The presence of three BAC ligands is a distinct feature relative to 4-W. Targeting a carbyne analog with the same number of BAC donors, compound $\mathbf{5}$ was treated with BAC; however, no reaction was observed, likely due to a combination of steric constraints and stability of the chelate.

For closer similarity to FeMoco, a Mo variant of the above clusters was targeted. The Mo-containing precursor 1-Mo was conveniently synthesized from $\left[\mathbf{N E t}_{4}\right]\left[\mathbf{T} \mathbf{p} * \mathbf{M o S}_{5}\right]$ via $\left[\mathbf{N E t}_{4}\right]$ [Tp* MoS ${ }_{3}$ (46) generated by sulfur abstraction with $\mathrm{PPh}_{3}(S I$ Appendix). Adapting the synthetic protocol developed for $\mathbf{2}-\mathbf{W}$, chloride substitution with BAC from 1-Mo allowed for the isolation of 2-Mo. Ring opening upon reduction with $\mathrm{KC}_{8}$ resulted in the formation of 4-Mo (Fig. 2). Notably, the $\mathrm{MoS}_{3} \mathrm{Fe}_{3} \mathrm{C}$ cluster core of 4-Mo reproduces one half of the structure of FeMoco, including the bridging carbon donor. Furthermore, the geometry of the unique $\mathrm{Fe}$ in the $\mathrm{C}$-bridged clusters $\mathbf{4 - W}$, 4-Mo, and 5 reproduces the four-coordinate, distorted trigonal pyramidal geometry found in the belt sites of FeMoco (Fig. 2). The S-Fe-S-C and SFe-S-N torsion angles in 4-W $\left(173.2^{\circ}\right)$ and $5\left(154.2^{\circ}\right)$ approach $180^{\circ}$, bringing these four atoms close to coplanar, which corresponds to a distorted trigonal pyramidal geometry at Fe, leaving

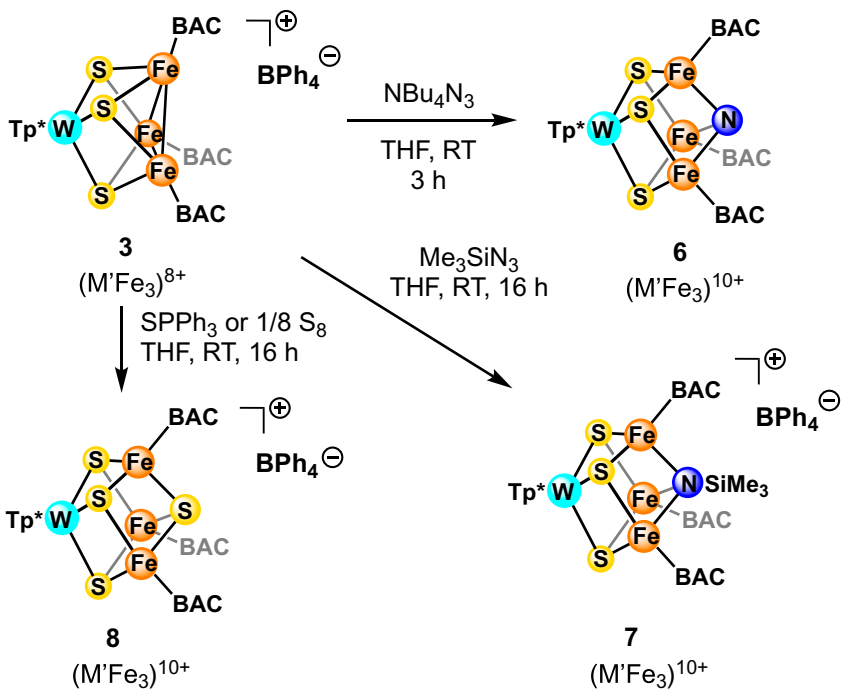

Fig. 3. Synthesis of nitride, imide, and sulfide-containing clusters.

the axial site open for potential substrate coordination, as has been previously invoked for $\mathrm{N}_{2}$ binding in FeMoco (17). In addition, the Fe-N distance in $\mathbf{5}$ is $2.16 \mathrm{~A}$, close to the Fe-N bond length in the previously characterized NH-bound FeVco $(2.01 \pm$ $0.04 \AA$ ) (31). Further studies are being conducted to investigate reactivity at this site.

A comparison of the structural aspects of the reported clusters and the corresponding subsite of FeMoco is informative (SI Appendix, Table S3). The W/Mo-S distances vary modestly (2.36 to $2.39 \AA)$ in the series of cubane complexes, suggesting that the metal oxidation state remains unchanged. Although the total redox state of the metal core varies from $\left(\mathrm{M}^{\prime} \mathrm{Fe}_{3}\right)^{8+}$ to $\left(\mathrm{M}^{\prime} \mathrm{Fe}_{3}\right)^{11+}$, it is likely that the formal oxidation state for $\mathrm{M}^{\prime}$ lies within the $3+/ 4+$ range, based on literature assignments for $\mathrm{MoFe}_{3} \mathrm{~S}_{4}(47)$ and $\mathrm{WFe}_{3} \mathrm{~S}_{4}(48)$ in two redox states, $\left(\mathrm{M}^{\prime} \mathrm{Fe}_{3}\right)^{10+}$ and $\left(\mathrm{M}^{\prime} \mathrm{Fe}_{3}\right)^{1+}$, as well as the trend in $\mathrm{M}^{\prime}-\mathrm{S}$ bond length as a function of oxidation states of $\mathrm{M}^{\prime}$ from related species (SI Appendix, Table S4). Comparison of bond lengths within the organic fragment supporting the carbyne ligand reveals notable differences in 4-W/4-Mo versus 5. In 4-W/4-Mo, the C10-N11 (average $1.36 \AA$ ) and C9-N18 (average $1.46 \AA$ ) distances are significantly different, suggesting multiple bonding character in C10-N11, while in 5 C10-N11 and C9-N12 are more similar [1. 47 (1) and 1.43 (1) $\AA$, respectively]. The orientation of N11 in 4-W/4-Mo is such that the lone pair can engage in delocalization within the olefin $\pi$ bond, increasing the $\mathrm{N}-\mathrm{C}$ bond order and lowering the C9-C10 bond order (SI Appendix, Fig. S33). Because the carbyne is directly bonded to the olefin, its character is linked to the propensity of the amine lone pair to delocalize, therefore rendering 4-W/4-Mo more Fischer-like than 5 (49). The possible changes in the character of the carbyne makes oxidation states ambiguous, but for consistency, herein the carbyne is assigned in the same way in all of the compounds. It is worth noting that the nature of the carbide ligand in FeMoco may also vary as a function of changes in the interactions with the other, remote metal centers. Additional experiments will be necessary to determine the overall redox states and distribution between metals; nevertheless, these compounds are in the range assigned for FeMoco (2). The structural parameters for the $\mathrm{W}$ and Mo analogs 4-W and 4-Mo are very similar, which suggests analogous redox distribution within the cluster despite different heterometals $\mathrm{M}^{\prime}$. The Fe-C distances in 4-W, 4-Mo, and $\mathbf{5}$ are in the range of 1.94 to $1.95 \AA$, which are close to the average Fe-C bond length in FeMoco of $2.00 \AA$ 


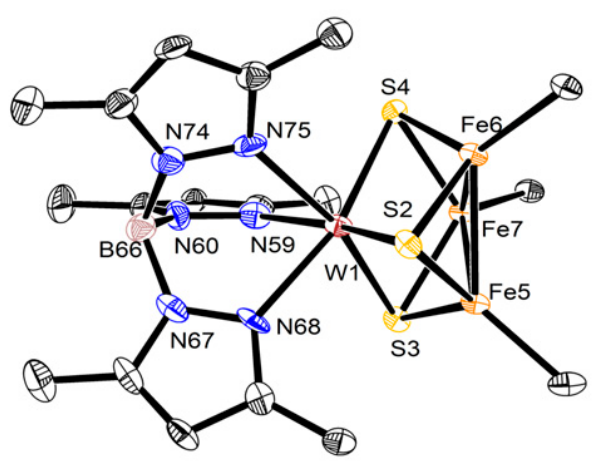

3

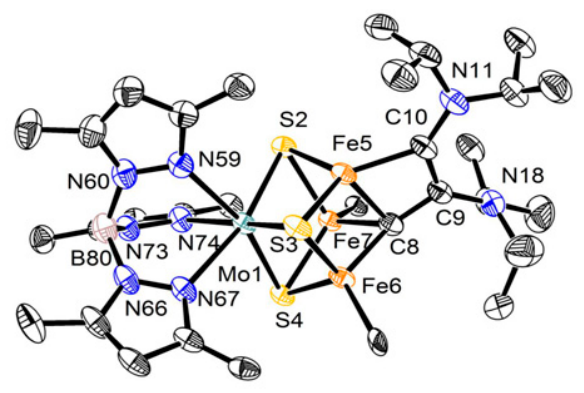

4-Mo

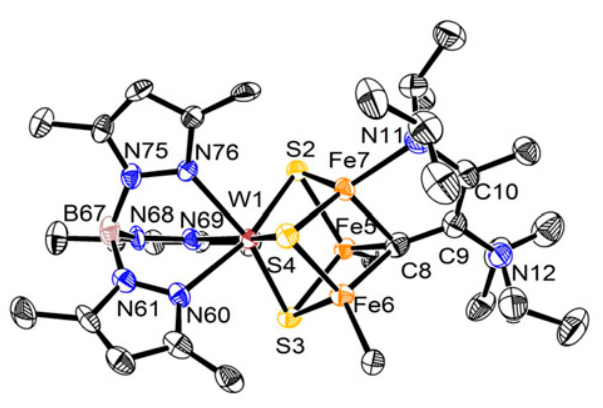

5



6

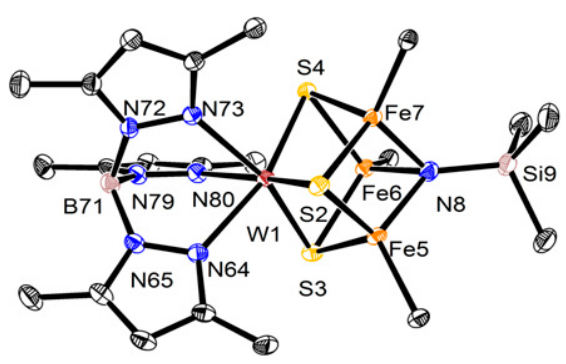

7



8

Fig. 4. Crystal structures of 3, 4-Mo, and $\mathbf{5}$ to $\mathbf{8}$ (reference SI Appendix for the isostructural cluster 4-W). Hydrogen atoms, counteranions (for 3, 5, 7, and 8), and the BAC ligand except for the carbene $C$ are omitted for clarity. Ellipsoids are shown at $50 \%$ probability.

(50), though shorter, likely due to bridging of the carbide between more metal centers in the biological system.

In order to probe the impact of structure on the redox potentials of the cubane models of FeMoco, we carried out a comparative cyclic voltammetry (CV) study of compounds 4 to 8 (Fig. 5). Each cluster displays at least one oxidation and one reduction event, both reversible. To assign the redox waves to the corresponding redox couple, starting from the structurally characterized complexes, the open-circuit potential of the system was determined prior to scanning reductively. For $\mathbf{6}, \mathbf{7}$, and $\mathbf{8}$, the two $\mathrm{CV}$ features are assigned to the $\left(\mathrm{M}^{\prime} \mathrm{Fe}_{3}\right)^{11+} /\left(\mathrm{M}^{\prime} \mathrm{Fe}_{3}\right)^{10+}$ and $\left(\mathrm{M}^{\prime} \mathrm{Fe}_{3}\right)^{10+} /\left(\mathrm{M}^{\prime} \mathrm{Fe}_{3}\right)^{9+}$ couples. For 4-W, 4-Mo, and 5, they correspond to $\left(\mathrm{M}^{\prime} \mathrm{Fe}_{3}\right)^{12+} /\left(\mathrm{M}^{\prime} \mathrm{Fe}_{3}\right)^{11+}$ and $\left(\mathrm{M}^{\prime} \mathrm{Fe}_{3}\right)^{11+} /\left(\mathrm{M}^{\prime} \mathrm{Fe}_{3}\right)^{10+}$. Compounds 4-W and 4-Mo show an additional reversible event at more positive potentials, assigned to $\left(\mathrm{M}^{\prime} \mathrm{Fe}_{3}\right)^{13+} /\left(\mathrm{M}^{\prime} \mathrm{Fe}_{3}\right)^{12+}$, which might be an indication of the carbyne ligand's ability to accommodate expanded redox capabilities. Compounds 4 to 8 can be compared using the $\left(\mathrm{M}^{\prime} \mathrm{Fe}_{3}\right)^{11+} /\left(\mathrm{M}^{\prime} \mathrm{Fe}_{3}\right)^{10+}$ couple (highlighted by boxes in Fig. 5), which they all display.

Although the compared redox event corresponds to the same formal oxidation state and metal coordination number across all clusters, there are several structural changes that can impact the reduction potentials and convolute interpretation: the identity of the bridging atom ( $\mathrm{C}$ versus $\mathrm{N}$ versus $\mathrm{S})$, the presence and nature of a chelate attached to the bridge, and the character of the bridging ligand stemming from its substituents (i.e., rotation of the amine and delocalization of its lone pair). Within the carbyne-containing clusters there is little impact of the identity of the Group 6 metal $\left(\mathrm{M}^{\prime}=\right.$ Mo versus $\mathrm{W})$ on the reduction potentials, with a slight increase in redox potential of $70 \mathrm{mV}$ on changing $\mathrm{W}$ to Mo, although the other biologically relevant $\mathrm{Fe}$ or $\mathrm{V}$ variants remain to be pursued. In biomimetic group transfer chemistry with Mo and W, a similarly modest increase in potentials of about $120 \mathrm{mV}$ is also observed for a nicotinic acid hydroxylase synthetic analog when Mo is replaced with W (51). The redox couple shifts positively by about $0.75 \mathrm{~V}$ between $\mathbf{4 - W}$ and $\mathbf{5}$, and a combination of structural changes support this trend: the positive charge of $\mathbf{5}$, the weaker electron donating capability of the $\mathrm{N}^{\mathrm{i}} \mathrm{Pr}_{2}$ group compared to the vinyl ligand, and the donation of the amine lone pair into the olefin $\pi$ system. The size of the carbyne chelate may also impact redox chemistry by changing the electronic 


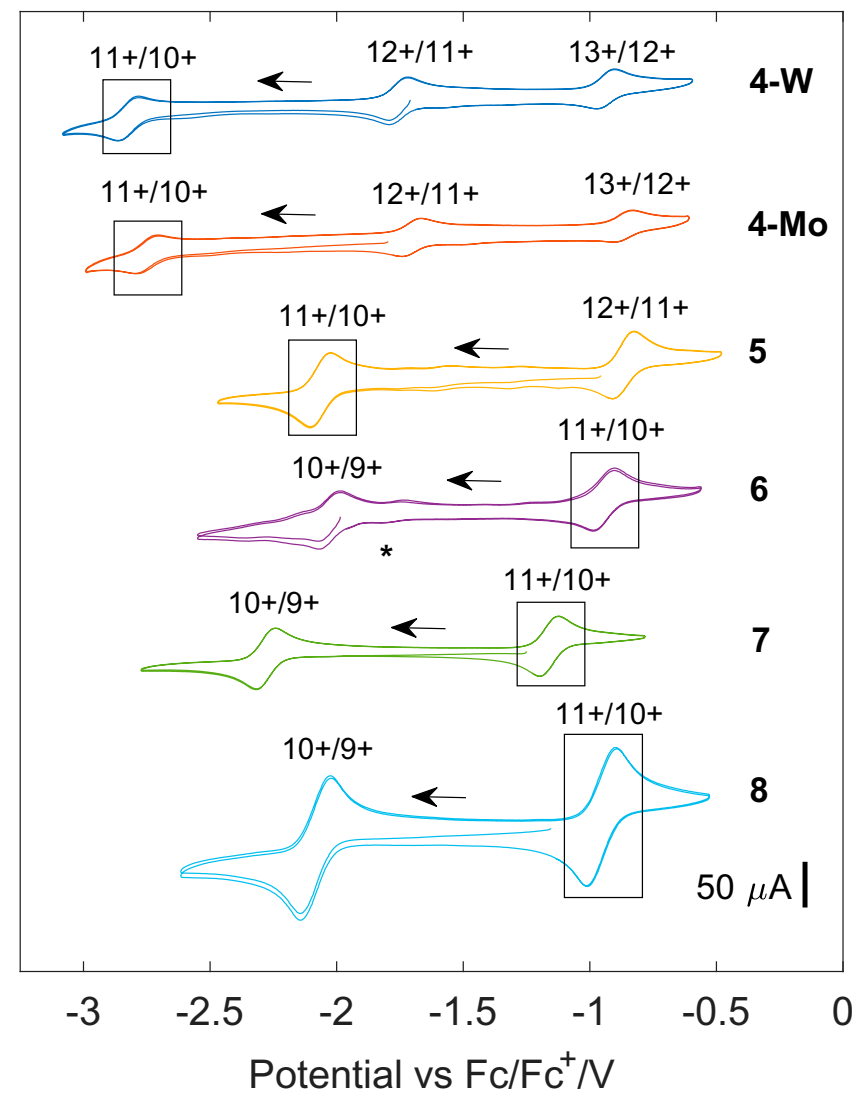

Fig. 5. CV scans for compounds 4 to 8 . Each voltammogram starts from the open-circuit potential, and the boxed peaks correspond to the $\left(\mathrm{M}^{\prime} \mathrm{Fe}_{3}\right)^{11+} /\left(\mathrm{M}^{\prime} \mathrm{Fe}_{3}\right)^{10+}$ couples of interest. The redox assignment is indicated above each wave in terms of the charge of the $\left(\mathrm{M}^{\prime} \mathrm{Fe}_{3}\right)$ metal core. Conditions: $2.5 \mathrm{mM}$ cluster in MeCN with $0.2 \mathrm{M} \mathrm{TBAPF}_{6}$, scan rates of $200 \mathrm{mV}$ $\mathrm{s}^{-1}$ (4-W, 5 to 8) or $250 \mathrm{mV} \mathrm{s}^{-1}$ (4-Mo). The asterisk indicates small amounts of 4-W impurity in samples of 6 .

character of the ligand. Osmium compounds supported by dppe versus dppm ligands show a relatively small change of $30 \mathrm{mV}$ (52), but we could not find specific precedent for the potential range of such effect for carbynes.

The $\left(\mathrm{M}^{\prime} \mathrm{Fe}_{3}\right)^{11+} /\left(\mathrm{M}^{\prime} \mathrm{Fe}_{3}\right)^{10+}$ couple for the C-containing clusters 4-W, 4-Mo, and $\mathbf{5}$ appear at potentials below $-2 \mathrm{~V}$, significantly more negative than for 6 to 8 at $-0.87 \mathrm{~V}$ to $-1.16 \mathrm{~V}$. While 6 to 8 contain three BAC ligands and 4-W/5 only have two, complicating comparison, compound $\mathbf{5}$ displays a weaker donor in the tertiary amine compared to BAC in 6 to 8 . Although a less ambiguous analysis would benefit from an ana$\log$ of $\mathbf{5}$ with a BAC ligand instead of the amine, which could not be accessed (vide supra), the greater electron donation ability of the NHC ligand compared to the tertiary amine is expected to render that hypothetical version of $\mathbf{5}$ even more reducing. Compounds 4-W, 4-Mo, and $\mathbf{5}$ all display chelates, unlike 6 to 8 . Multidentate phosphines and pyridines show shifts of less than $0.3 \mathrm{~V}$ in redox potentials relative to monodentate variants (52). Although this difference is much smaller than the differences observed here, because the carbyne interactions may be more strongly impacted by changes in bond angles, we cannot rule out that changes in reduction potentials are primarily due the presence of chelates in 4-W, 4-Mo, and $\mathbf{5}$. Overall, the combination of carbyne and chelate results in a remarkable redox potential difference. Compounds 5 and 6 maintain the same formal charge for the bridging ligand (3-) as carbyne versus nitride. Still, a difference in the $\left(\mathrm{M}^{\prime} \mathrm{Fe}_{3}\right)^{11+} /$ $\left(\mathrm{M}^{\prime} \mathrm{Fe}_{3}\right)^{10+}$ redox potentials of $1.12 \mathrm{~V}$ is observed, a substantial impact of the chelating C- versus N-based, though nonchelating, ligands. Changing the donor from nitride (6) to imide (7) or sulfide (8) shifts the redox potential less than $200 \mathrm{mV}$, highlighting the similar effect of $\mathrm{S}$ and $\mathrm{N}$ donors on the redox chemistry, in contrast to the chelating carbyne.

These electrochemical results suggest that the interstitial carbon ligand in FeMoco may play an important role in increasing the reductive power of the clusters. While the specific oxidation states of the metal centers cannot be verified without additional spectroscopic studies, the reduced form, $\left(\mathrm{M}^{\prime} \mathrm{Fe}_{3}\right)^{10+}$, corresponds to an average metal oxidation state of 2.5 (or 2 if a Fischer carbyne resonance is considered), close to the resting state of FeMoco as $\mathrm{Fe}^{\mathrm{II}}{ }_{3} \mathrm{Fe}^{\mathrm{III}}{ }_{4} \mathrm{Mo}^{\mathrm{III}}$ (average metal oxidation state 2.6) (2). Additional reduction steps lower the average formal oxidation state of FeMoco, but not below 2, and do not bring it in the range typically observed for mononuclear $\mathrm{Fe}$ complexes studied for $\mathrm{N}_{2}$ activation (53). Therefore, the ability of the biological cofactor to perform $\mathrm{N}_{2}$ activation at high oxidation states is unusual. A possible explanation is charge redistribution within the cluster to increase reducing equivalents at the site of substrate binding or electronic communication between different metal sites $(21-23,54)$. We find here that the chelating carbyne ligand has a remarkable impact on the cluster reduction potentials, with very reducing potentials for relatively high, biologically relevant metal oxidation states. Moreover, the chelating carbyne clusters are significantly more reducing for the same redox state compared to $\mathrm{N}$ and $\mathrm{S}$ analogs. It is important to note that the chelation present in all carbynes reported here and the delocalization of amine lone pair in some of them may have a substantial effect on the redox chemistry by tuning the electronic properties of the carbon ligand; conceptually related, changes in the coordination environment of distal iron centers in FeMoco may have similar effects on the carbide.

Toward addressing the effect of the interstitial ligands of FeMoco, we have reported studies of tetranuclear Fe clusters with $\mu_{4}$-fluoride and oxide ligands (21). In those cases, the oxide makes the cluster about $1 \mathrm{~V}$ more reducing compared to fluoride for the same redox state while also promoting NO activation. Additionally, remote metal centers affect reactivity through interactions with the bridging moiety $(\mathrm{O}$ or $\mathrm{F})$. In those systems, the charge of the interstitial atom could play a role in changing the potential. Here, this series of clusters accounts for changes in ligand charge. Chelating carbyne (5) and nitride (6) ligands have the same formal charge but result in $\sim 1 \mathrm{~V}$ difference in reducing power, in contrast with the nitride (6), imide (7), and sulfide (8) species that have reduction potentials within $300 \mathrm{mV}$. The ability of the chelating carbyne to increase the reduction power is likely a consequence of its stronger interaction with the metal centers, an aspect that will be pursued in a separate study, including nonchelated targets.

In the context of $\mathrm{N}_{2}$ reduction, the redox tuning observed here suggests that the interstitial carbon may allow FeMoco to access higher reducing power, enabling more facile transfer of electrons to the $\mathrm{N}_{2}$ substrate for conversion to $\mathrm{NH}_{3}$. This parallels the results from experiments using synthetic iron catalysts for $\mathrm{N}_{2}$ reduction, many of which require strong external reducing agents like $\mathrm{KC}_{8}(8,55)$. Considering the potential impact of replacing the bridging carbyne with a more biologically inexpensive sulfide, a much less reducing cluster $(\mathbf{8})$ is generated for the same redox state, $\left(\mathrm{M}^{\prime} \mathrm{Fe}_{3}\right)^{10+}$, and even an additional reducing equivalent in $\left(\mathrm{M}^{\prime} \mathrm{Fe}_{3}\right)^{9+}$ does not match with the $\left(\mathrm{M}^{\prime} \mathrm{Fe}_{3}\right)^{9+}$ carbyne system. Therefore, an interstitial sulfide may not provide sufficient reducing power to efficiently convert $\mathrm{N}_{2}$ into $\mathrm{NH}_{3}$, leading instead to the preference for the unusual bridging carbide motif.

In summary, we have described the synthesis of a series of heterometallic iron-sulfur clusters of the form $\mathrm{M}^{\prime} \mathrm{Fe}_{3} \mathrm{~S}_{3} \mathrm{X}\left(\mathrm{M}^{\prime}=\right.$ 
Mo or $\mathrm{W}$ and $\mathrm{X}=\mathrm{CR}, \mathrm{N}, \mathrm{NR}$, and $\mathrm{S}$ ) with the cubane geometry matching the structure of the $\mathrm{MFe}_{3} \mathrm{~S}_{3} \mathrm{C}$ subsite of FeMco. These include examples of iron-sulfur clusters containing a chelating carbon-based ligand bridging the $\mathrm{Fe}_{3}$ face. Importantly, electrochemical studies indicate that the presence of a bridging $\mathrm{C}$-donor in combination with electronic tuning (by chelation and amine lone pair delocalization) allows the clusters to reach highly reducing states, with potential implications for $\mathrm{N}_{2}$ reduction chemistry. These studies shed light on possible structural and electrochemical roles of the interstitial carbide ligand in nitrogenase.

\section{Materials and Methods}

All reactions were performed at room temperature in a $\mathrm{N}_{2}$-filled MBraun glovebox or using standard Schlenk techniques unless otherwise specified. Solvents were dried by sparging with $\mathrm{N}_{2}$ for at least $15 \mathrm{~min}$ and then passing through a column of activated alumina under positive $\mathrm{N}_{2}$ pressure and stored over molecular sieves prior to use. All experimental conditions and procedures, spectroscopic data, and details of characterization of compounds [NEt 4 ] $\left[\mathrm{Tp}^{*} \mathrm{MoS}_{3}\right]$ and $\mathbf{1}$ to $\mathbf{8}$ are given in SI Appendix. CV experiments were

1. B. K. Burgess, D. J. Lowe, Mechanism of molybdenum nitrogenase. Chem. Rev. 96, 2983-3012 (1996).

2. T. Spatzal et al., Nitrogenase FeMoco investigated by spatially resolved anomalous dispersion refinement. Nat. Commun. 7, 10902 (2016)

3. P. E. M. Siegbahn, Model calculations suggest that the central carbon in the FeMocofactor of nitrogenase becomes protonated in the process of nitrogen fixation. $J$. Am. Chem. Soc. 138, 10485-10495 (2016).

4. I. Corić, B. Q. Mercado, E. Bill, D. J. Vinyard, P. L. Holland, Binding of dinitrogen to an iron-sulfur-carbon site. Nature 526, 96-99 (2015).

5. G. Ung, J. C. Peters, Low-temperature $\mathrm{N}_{2}$ binding to two-coordinate $\mathrm{L}_{2} \mathrm{Fe}^{0}$ enables reductive trapping of $\mathrm{L}_{2} \mathrm{FeN}_{2}{ }^{-}$and $\mathrm{NH}_{3}$ generation. Angew. Chem. Int. Ed. Engl. 54, 532-535 (2015).

6. S. F. McWilliams et al., Coupling dinitrogen and hydrocarbons through aryl migration. Nature 584, 221-226 (2020).

7. A. L. Nagelski et al., The influences of carbon donor ligands on biomimetic multi-iron complexes for $\mathrm{N}_{2}$ reduction. Chem. Sci. (Camb.) 11, 12710-12720 (2020).

8. S. E. Creutz, J. C. Peters, Catalytic reduction of $\mathrm{N}_{2}$ to $\mathrm{NH}_{3}$ by an Fe- $\mathrm{N}_{2}$ complex featuring a C-atom anchor. J. Am. Chem. Soc. 136, 1105-1115 (2014).

9. C. H. Arnett, T. Agapie, Activation of an open shell, carbyne-bridged diiron complex toward binding of dinitrogen. J. Am. Chem. Soc. 142, 10059-10068 (2020).

10. C. Joseph, C. R. Cobb, M. J. Rose, Single-step sulfur insertions into iron carbide carbonyl clusters: Unlocking the synthetic door to FeMoco analogues. Angew. Chem. Int. Ed. Engl. 60, 3433-3437 (2021)

11. L. Liu, T. B. Rauchfuss, T. J. Woods, Iron carbide-sulfide carbonyl clusters. Inorg. Chem. 58, 8271-8274 (2019).

12. S. Ohta, Y. Ohki, T. Hashimoto, R. E. Cramer, K. Tatsumi, A nitrogenase cluster model $\left[\mathrm{Fe}_{8} \mathrm{~S}_{6} \mathrm{O}\right]$ with an oxygen unsymmetrically bridging two proto- $\mathrm{Fe}_{4} \mathrm{~S}_{3}$ cubes: Relevancy to the substrate binding mode of the FeMo cofactor. Inorg. Chem. 51, 11217-11219 (2012).

13. Y. Ohki, Y. Ikagawa, K. Tatsumi, Synthesis of new [8Fe-7S] clusters: A topological link between the core structures of P-cluster, FeMo-co, and FeFe-co of nitrogenases. J. Am. Chem. Soc. 129, 10457-10465 (2007).

14. T. M. Powers, T. A. Betley, Testing the polynuclear hypothesis: Multielectron reduction of small molecules by triiron reaction sites. J. Am. Chem. Soc. 135, 12289-12296 (2013).

15. A. Sridharan, A. C. Brown, D. L. M. Suess, A terminal imido complex of an iron-sulfur cluster. Angew. Chem. Int. Ed. Engl. 60, 12802-12806 (2021).

16. A. McSkimming, D. L. M. Suess, Dinitrogen binding and activation at a molybdenumiron-sulfur cluster. Nat. Chem. 13, 666-670 (2021).

17. D. E. DeRosha et al., Planar three-coordinate iron sulfide in a synthetic [4Fe-3S] cluster with biomimetic reactivity. Nat. Chem. 11, 1019-1025 (2019).

18. G. Xu, J. Zhou, Z. Wang, R. H. Holm, X.-D. Chen, Controlled incorporation of nitrides into W-Fe-S clusters. Angew. Chem. Int. Ed. Engl. 58, 16469-16473 (2019).

19. Y. Lee et al., Dinitrogen activation upon reduction of a triiron(II) complex. Angew. Chem. Int. Ed. Engl. 54, 1499-1503 (2015).

20. M. Reiners et al., $\mathrm{NH}_{3}$ formation from $\mathrm{N}_{2}$ and $\mathrm{H}_{2}$ mediated by molecular tri-iron complexes. Nat. Chem. 12, 740-746 (2020)

21. C. J. Reed, T. Agapie, Tetranuclear Fe clusters with a varied interstitial ligand: Effects on the structure, redox properties, and nitric oxide activation. Inorg. Chem. 56, 13360-13367 (2017)

22. C. H. Arnett, M. J. Chalkley, T. Agapie, A thermodynamic model for redox-dependent binding of carbon monoxide at site-differentiated, high spin iron clusters. J. Am. Chem. Soc. 140, 5569-5578 (2018).

23. C. H. Arnett, J. T. Kaiser, T. Agapie, Remote ligand modifications tune electronic distribution and reactivity in site-differentiated, high-spin iron clusters: Flipping scaling relationships. Inorg. Chem. 58, 15971-15982 (2019). performed with a Pine Instrument Company AFCBP1 bipotentiostat in a threeelectrode cell, which consisted of glassy carbon (working; $\varphi=3.0 \mathrm{~mm}$ ), Ag wire (reference), and bare Pt wire (counter), in a $\mathrm{N}_{2}$-filled MBraun glovebox at room temperature; dry $\mathrm{CH}_{3} \mathrm{CN}$ that contained $0.2 \mathrm{M}\left[\mathrm{Bu}_{4} \mathrm{~N}\right]\left[\mathrm{PF}_{6}\right]$ was used as the electrolyte solution.

Data Availability. Atomic coordinates and structure factors data have been deposited in the Cambridge Structural Database (CSD) of the Cambridge Crys tallographic Data Centre (https://www.ccdc.cam.ac.uk/structures/). CSD refer ence numbers are as follows: 2084246 (1-Mo), 2081620 (2-W), 2084269 (2-Mo) 2081619 (3), 2081616 (4-W), 2084247 (4-Mo), 2081621 (5), 2081617 (6) 2081622 (7), and 2084054 (8). All other study data are included in the article and/or SI Appendix.

ACKNOWLEDGMENTS. We are grateful to the NIH (R01-GM102687B to T.A.) Natural Sciences and Engineering Research Council of Canada (G.A.B.), the Resnick Sustainability Institute at Caltech (G.A.B.), and the NSF (Graduate Research Fellowships Program to A.G.S.) for funding. We thank the Beckman Institute and the Dow Next Generation Grant for instrumentation support. Michael Takase, Lawrence Henling, and Manar Shoshani are thanked for assis tance with crystallography.

24. C. Joseph, S. Kuppuswamy, V. M. Lynch, M. J. Rose, Fe ${ }_{5}$ Mo cluster with iron-carbide and molybdenum-carbide bonding motifs: Structure and selective alkyne reductions. Inorg. Chem. 57, 20-23 (2018).

25. M. R. Churchill, J. Wormald, J. Knight, M. J. Mays, Synthesis and crystallographic characterization of bis(tetramethylammonium) carbidohexadecacarbonylhexaferrate, a hexanuclear carbidocarbonyl derivative of iron. J. Am. Chem. Soc. 93, 3073-3074 (1971).

26. J. McGale, G. E. Cutsail III, C. Joseph, M. J. Rose, S. DeBeer, Spectroscopic X-ray and Mössbauer characterization of $M_{6}$ and $M_{5}$ iron(molybdenum)-carbonyl carbide clusters: High carbide-iron covalency enhances local iron site electron density despite cluster oxidation. Inorg. Chem. 58, 12918-12932 (2019).

27. J. S. Bradley, G. B. Ansell, M. E. Leonowicz, E. W. Hill, Synthesis and molecular struc ture of $\mu_{4}$-carbido- $\mu_{2}$-carbonyl-dodecacarbonyltetrairon, a neutral iron butterfly cluster bearing an exposed carbon atom. J. Am. Chem. Soc. 103, 4968-4970 (1981).

28. C. H. Arnett et al., Mixed-valent diiron $\mu$-carbyne, $\mu$-hydride complexes: Implications for nitrogenase. J. Am. Chem. Soc. 142, 18795-18813 (2020).

29. T. Spatzal, K. A. Perez, J. B. Howard, D. C. Rees, Catalysis-dependent selenium incorporation and migration in the nitrogenase active site iron-molybdenum cofactor eLife 4, e11620 (2015)

30. T. Spatzal, K. A. Perez, O. Einsle, J. B. Howard, D. C. Rees, Ligand binding to the FeMocofactor: Structures of CO-bound and reactivated nitrogenase. Science 345, 1620-1623 (2014)

31. D. Sippel et al., A bound reaction intermediate sheds light on the mechanism of nitrogenase. Science 359, 1484-1489 (2018).

32. G. Xu et al., Ligand metathesis as rational strategy for the synthesis of cubane-type heteroleptic iron-sulfur clusters relevant to the FeMo cofactor. Proc. Natl. Acad. Sci. U.S.A. 115, 5089-5092 (2018)

33. D. V. Fomitchev, C. C. McLauchlan, R. H. Holm, Heterometal cubane-type $\left.\mathrm{MFe}_{3} \mathrm{~S}_{4}\right)$ clusters ( $\mathrm{M}=\mathrm{Mo}, \mathrm{V})$ trigonally symmetrized with hydrotris(pyrazolyl)borate(1-) and tris(pyrazolyl)methanesulfonate(1-) capping ligands. Inorg. Chem. 41, 958-966 (2002)

34. D. Hong, Y. Zhang, R. H. Holm, Heterometal cubane-type $\mathrm{WFe}_{3} \mathrm{~S}_{4}$ and related clusters trigonally symmetrized with hydrotris(3,5-dimethylpyrazolyl)borate. Inorg. Chim. Acta 358, 2303-2311 (2005).

35. V. Lavallo, Y. Ishida, B. Donnadieu, G. Bertrand, Isolation of cyclopropenylidenelithium adducts: The Weiss-Yoshida reagent. Angew. Chem. Int. Ed. Engl. 45, 6652-6655 (2006)

36. J. L. Martinez et al., Cyanide ligand assembly by carbon atom transfer to an iron nitride. J. Am. Chem. Soc. 139, 14037-14040 (2017)

37. L. Deng, R. H. Holm, Stabilization of fully reduced iron-sulfur clusters by carbene ligation: The $\left[\mathrm{Fe}_{n} \mathrm{~S}_{n}\right]^{0}$ oxidation levels $(n=4,8)$. J. Am. Chem. Soc. 130, 9878-9886 (2008).

38. M. E. Evans, T. Li, W. D. Jones, $\mathrm{C}-\mathrm{H}$ vs $\mathrm{C}-\mathrm{C}$ bond activation of acetonitrile and benzonitrile via oxidative addition: Rhodium vs nickel and $\mathrm{Cp}^{*}$ vs $\mathrm{Tp}^{\prime}\left(\mathrm{Tp}^{\prime}=\right.$ hydrotris(3,5dimethylpyrazol-1-yl)borate, $\mathrm{Cp}^{*}=\eta(5)$-pentamethylcyclopentadienyl). J. Am. Chem. Soc. 132, 16278-16284 (2010).

39. G. T. Kent, S. L. Staun, G. Wu, T. W. Hayton, Reactivity of $\left.\left[\mathrm{Ce}\left(\mathrm{NR}_{2}\right)_{3}\right](\mathrm{R}=\mathrm{SiMe})_{3}\right)$ with prospective carbon atom transfer reagents. Organometallics 39, 2375-2382 (2020)

40. C. T.-W. Chu, L. F. Dahl, Structural characterization of $\left[\mathrm{AsPh}_{4}\right]^{+}\left[\mathrm{Fe}_{4}(\mathrm{NO})_{7}\left(\mu_{3}-\mathrm{S}\right)_{3}\right]^{-}$Stereochemical and bonding relationship of the Roussin black monoanion with the red ethyl ester, $\mathrm{Fe}_{2}(\mathrm{NO})_{4}\left(\mu_{2}-\mathrm{SC}_{2} \mathrm{H}_{5}\right)_{2}$, and $\mathrm{Fe}_{4}(\mathrm{NO})_{4}\left(\mu_{3}-\mathrm{S}\right)_{4}$. Inorg. Chem. 16, 3245-3251 (1977).

41. J. Fritsch et al., The crystal structure of an oxygen-tolerant hydrogenase uncovers a novel iron-sulphur centre. Nature 479, 249-252 (2011)

42. D. Coucouvanis, J. Han, N. Moon, Synthesis and characterization of sulfur-voided cubanes. Structural analogues for the $\mathrm{MoFe}(3) \mathrm{S}(3)$ subunit in the nitrogenase cofactor. J. Am. Chem. Soc. 124, 216-224 (2002). 
43. T. M. Powers, A. R. Fout, S.-L. Zheng, T. A. Betley, Oxidative group transfer to a triiron complex to form a nucleophilic $\mu\left({ }_{3}\right)$-nitride, $\left[\mathrm{Fe}_{3}\left(\mu\left({ }_{3}\right)-\mathrm{N}\right)\right]$. J. Am. Chem. Soc. 133 3336-3338 (2011).

44. M. Horitani et al., Radical SAM catalysis via an organometallic intermediate with an Fe-[5'-C]-deoxyadenosyl bond. Science 352, 822-825 (2016).

45. M. Ye, N. B. Thompson, A. C. Brown, D. L. M. Suess, A synthetic model of enzymatic $\left[\mathrm{Fe}_{4} \mathrm{~S}_{4}\right]$-alkyl intermediates. J. Am. Chem. Soc. 141, 13330-13335 (2019).

46. T. J. Sherbow, L. N. Zakharov, D. W. Johnson, M. D. Pluth, Hydrosulfide oxidation at a molybdenum tetrasulfido complex. Inorg. Chem. 59, 15574-15578 (2020).

47. J. K. Kowalska et al., X-ray magnetic circular dichroism spectroscopy applied to nitrogenase and related models: Experimental evidence for a spin-coupled molybdenum(III) center. Angew. Chem. Int. Ed. Engl. 58, 9373-9377 (2019).

48. A. Majumdar, R. H. Holm, Specific incorporation of chalcogenide bridge atoms in molybdenum/tungsten-iron-sulfur single cubane clusters. Inorg. Chem. 50, 11242-11251 (2011).

49. A. L. Colebatch, B. J. Frogley, A. F. Hill, C. S. Onn, Pnictogen-functionalised $C_{1}$ ligands: $M C-A R_{n}(n=0,1,2,3)$. Chemistry 27, 5322-5343 (2021).
50. T. Spatzal et al., Evidence for interstitial carbon in nitrogenase FeMo cofactor. Science 334, 940 (2011).

51. H. Tano, R. Tajima, H. Miyake, S. Itoh, H. Sugimoto, Selenidobis(dithiolene)metal(IV) complexes (metal $\mathrm{M}=\mathrm{Mo}, \mathrm{W}$ ) potentially related to the nicotinic acid hydroxylase reaction center: Redox aspects in electrochemistry and oxygen atom transfer from $\mathrm{Me}_{3} \mathrm{NO}$ to $\mathrm{M}\left({ }^{\mathrm{IV}}\right)$ centers. Inorg. Chem. 47, 7465-7467 (2008).

52. A. B. P. Lever, Electrochemical parametrization of metal complex redox potentials, using the ruthenium(III)/ruthenium(II) couple to generate a ligand electrochemical series. Inorg. Chem. 29, 1271-1285 (1990).

53. I. Čorić, P. L. Holland, Insight into the iron-molybdenum cofactor of nitrogenase from synthetic iron complexes with sulfur, carbon, and hydride ligands. J. Am. Chem. Soc 138, 7200-7211 (2016).

54. J. T. Henthorn et al., Localized electronic structure of nitrogenase FeMoco revealed by selenium $\mathrm{K}$-edge high resolution X-ray absorption spectroscopy. J. Am. Chem. Soc 141, 13676-13688 (2019).

55. A. L. Speelman et al., Nitrogenase-relevant reactivity of a synthetic iron-sulfur-carbon site. J. Am. Chem. Soc. 141, 13148-13157 (2019). 